\title{
DIGITALNO MODELOVANJE TURISTIČKIH DESTINCIJA
}

\author{
Nenad B. Tanasić, Branislav R. Tanasić ${ }^{1}$
}

\begin{abstract}
Sažetak
Poput tradicionalnih kanala marketinga, tako su i digitalni marketinški kanali u funkciji da vrednost proizvoda ili usluga prenesu sa proizvođača odnosno davaoca usluga na krajnjeg potrošača. Digitalni marketing obuhvata brojne marketinške kanale, uz nisku cenu promovisanja i mogućnosti da istovremeno dopre do velikog broja potencijalnih potrošača, predstavlja izuzetno efikasan model savremenog promovisanja. Aplikacije na mobilnim uređajima omogućavaju širok spektar primene, ali i veliki su izazov marketarima. Primena raznovrsnih ogranivača promotivnih poruka i banera, u prvom redu Tivo koji sprečava TV reklamne poruke, zatim Adblocker, zadužen za eliminisanje poruka na mobilnim uređajima, velika su prepreka u palsiranju promotivnih poruka. Treba imati u vidu i moždanu filtraciju, kojom mozak neinteresantne sadržaje, u koje se najčešće ubrajaju promotivne poruke, jednostavno ignoriše, tako da sadržaji koji nisu u fokusu pažnje, nisu se desili i neće biti zapamćeni.
\end{abstract}

Ključne reči: Turizam, destinacija, digitalan, virtuelna realnost, proširena realnost

\section{DIGITAL MODELING OF TOURIST DESTINATIONS}

\begin{abstract}
Like traditional marketing channels, digital marketing channels have the function of transferring the value of products or services from the producer or service provider to the end consumer. Digital marketing encompasses numerous marketing channels, with a low cost of promotion and the ability to simultaneously reach a large number of potential consumers, is an extremely effective model of modern promotion. Mobile applications provide a wide range of applications, but they are also a great challenge for marketers. The application of various promotional message and banner limiters, first of all Tivo which prevents TV
\end{abstract}

1 Fakultet za menadžment u Sremskim Karlovcima, Univerzitet “Union-Nikola Tesla” u Beogradu e-mail: tanasicbrana@yahoo.com 
advertising messages, then Adblocker, which is in charge of eliminating messages on mobile devices, are a big obstacle in the palsing of promotional messages. We should also keep in mind brain filtration, by which the brain simply ignores uninteresting content, which most often includes promotional messages, so the content that is not in the focus of attention,did not happen and will not be remembered.

Keywords: Tourism, destination, digital, virtual reality, augmented reality

\section{UVOD}

Brojne su definicije turističke destinacije, ukratko, može se reći da je to lokacija turističke potrošnje. Za mesto koja ima status turističke destinacije, podrazumeva se da je u izvesnoj meri brendirana lokacija za koju se zna i koju turisti već posećuju. Kako izgraditi brend, kako promovisati lokaciju koja tek treba da se afirmiše kao turistička destinacija? Za koji se marketinški pristup, alat i komunikacioni kanal opredeliti, dovoljno atraktivan da proizvede željeni efekat, da to sve ne bude tek još jedna reklama u nizu. $U$ visokourbanim sredinama ljudi su okruženi advertajzingom na svakom koraku, tako Hood u svojoj knjizi Selling the dream, konstatuje izuzetnu količinu promotivnih informacija kojima su izloženi građani SAD-a za vreme 17 časova dnevnih aktivnosti: "Tokom tipičnog dana, prosečan Amerikanac vidi preko 5000 reklama" (Hood, 2005: 119-120). Šta od tako velikog broja reklama uopšte dopire do svesti, u kojoj meri ima efekat na ciljanog primaoca promotivne poruke, osnovna su pitanja koja se nameću marketarima, kreatorima tih sadržaja. Svesna sfera mozga se od najezde informacija brani filtriranjem, nepropusnom barijerom za nevažne podatke u koje se najčešće svrstavaju i propagandne poruke. Psihički život čoveka je organizovan tako da je većina moždanih procesa automatska, na podsvesnom nivou, stoga je to je prostor na koji će marketari atakovati sve više, pa se u oblikovanju i realizaciji promotivnih aktivnosti kombinuju saznanja više naučnih oblasti i raznovrsne tehnike, u prvom redu psihologije. Davne 1904. godine Skot (Walter Scott), u svom radu The Psychology of Advertising, nedvosmisleno anticipira razvojni put $\mathrm{i}$ značaj primene psihologije u promociji: "Oglašavanje je osnovni faktor modernih poslovnih metoda, i što je mudrije, poslovni ljudi mogu bolje razumeti način razmišljanja svojih potrošača, moraju znati kako da na njih utiču efektnije - moraju znati kako da primene psihologiju u oglašavanju" (Scott, 1904: 33-34). 


\section{DIGITALIZOVANJE DESTINACIJE}

Ljudi su se od davnina dovijali kako da neki bitan događaj zabeleže, sačuvaju ili prenesu poruku drugima. Tako su se razvili pećinski crteži i petroglifi. Prvi portabl uređaj za beleženje i prenos bio je običan drveni štap ili životinjska kost. Urezivanjem određenih znakova i simbola zapis bi ostajao stalan, lako prenosiv i uvek dostupan. Jasno da ljudi na takvom stepenu razvoja nisu imali potrebe za komplikovanim porukama. Tehnološki razvoj iskazuje neophodnost operisanja velikim brojem sve složenijih informacija, tako da bi uređaj koji bi bio u stanju da skladišti i ubrza obradu takvih podataka, bio više nego koristan. Stepen razvoja tehničkih sredstava determiniše način na koji su razvijani pokušaji u rešavanju ovako izuzetno zahtevnog zadatka. Dizajn je u početku predstavljao čisto mehaničku napravu, (Antička Antikithera ili na primer Babidge Difference Engine).

Charles Babbage, godine 1822. osmislio je i počeo sa radovima na svojoj Diferencijalnoj mašini (Difference Engine), koja se beleži u istoriji kao prva automatska računska mašina. Predvidjena je bila da operiše višecifrenim brojevima i da odštampa rezultat. Na žalost, nedostatak novca sprečio je inovatora da završi započeto. $U$ čast dve stotine godina od rođenja velikog pronalazača, London Science Museum, je 1991. godine kompletirao mašinu nazvavši je Difference Engine No2.

Razvojem elektrifikacije usavršavaju se konstrukcije i pojavljuju se kombinovani elektro-mehanički uređaji (Holerith Tabulator, zatim Vannaver Bush mašina, ili serija uređaja koje razvio Konrad Zuse). Razvoj vakuumskih cevi omogućava izgradnju prvog programibilnog digitalnog računara Kolos (Colossus). Kompjuter Kolos aktiviran je u januaru, 1944. godine, u Bletchley Park, (britanski Centar za šifrovanje i dešifrovanje) i istakao se kao značajna pomoć britanskim dešifrantima u razbijanju kodiranih poruka. Prvi digitalni računar ENIAC, pokrenut je 1946. godine. Čudo elektronike svoga doba, sa preko sedamnaest hiljada elektronskih vakuumskih cevi, 300 puta brži od britanskog Mark I Colossus kompjutera (Copeland, 2005: 64-77).

Pronalazak tranzistora bitno smanjuje gabarite uređaja i potrošnju električne energije. Tranzistorska tehnika otvara prostor za proizvodnju znatno jeftinijih uređaja, da bi pravi bum u razvoju računara i elektronike uopšte, omogućio razvoj mikro čipa, elektronska poluprovodnička komponenta koja u sebi objedinjuje stotine hiljada, a kasnije i milione tranzistora. Put za razvoj digitalnih sredstava bio je širom otvoren, što je rezultiralo razvojem cenovno prihvatljivih, svima dostupnih računarskih uređaja. Uporedo sa razvojem kompjutera razvija se i širi internet mreža, tako se na taj način upotpunio scenario za razvoj internet komuniciranja kao i apliciranje digitalnog marketinga. Termin digitalni marketing, 
skovan je devedesetih godina prošlog veka. Zapravo, prvi korak u pravcu razvoja digitalne komunikacije načinjen je još 1971. godine, kada je Ray Tomilson uspešno poslao prvu Email poruku. Bio je to kamen temeljac na koji se ubrzo nadograđuje elektronski bum dot.com mreža i servisa. Računa se da je 1955. godine bilo svega 250 kompjutera u celom svetu. Godine 1980. prodato je preko milion personalnih uređaja. Razvoj interneta eksponencijalno uvećava broj korisnika, tako da prema najnovijim podacima Internet Usage Statistics, u svetu ima više od 4,6 milijardi registrovanih korisnika interneta (Internet Usage Statistic, 2020).

Razvoj mobilnih telefona doneo je svojevrstan paradoks. $U$ razvijenim zemljama broj pretplatnika mobilne telefonije daleko je veći od broja stanovnika. Tako se računa da na 100 stanovnika dolazi 179 mobilnih uređaja, dok u zemljama u razvoju taj odnos je, u proseku, 89 na 100 stanovnika. Procenjuje se da će broj mobilnih uređaja u 2020. godini dostići 14,02 milijardi, što daleko prevazilazi broj stanovnika planete 7,7 milijardi (Statista, 2020).

Kratak pregled razvoja računara i globalnog umreženja ilustruje silne napore uložene u kreiranje i unapređenje ovih uređaja. Da li su vizionari razvoja računara mogli da predvide u kojoj su meri danas prisutne informacione tehnologije i kako je pored ostalog, taj moćan marketinški potencijal zapravo digitalizovao živote svih. Internet je globalizovao tržište, izbrisao geografske granice, vremenske zone, i na taj način prilično izjednačio mogućnosti svih da prezentuju svoje potencijale.

Na početku je postavljeno pitanje o promovisanju lokacije, pokušaju izgradnje brenda na turističkoj mapi. Računa se da na turističkom tržištu egzistira negde preko deset hiljada turističkih destinacija. Više je nego izazov dodati još jednu lokaciju na tako masovnu ponudu. Računar je kompleksan elektronski uređaj, takvog dizajna i arhitekture u mogućnosti da obavlja najsloženije operacije, tako da su u digitalnom kreiranju promocije turističke destinacije, jedini limitirajući faktori znanje i maštovitost dizajnera. Za razliku od TV programa, gde gledalac odabira neki od brojnih televizijskih kanala, i tu se njegova mogućnost izbora završava, korisnik računara, iz gotovo neograničene ponude tema, sam odabira sadržaj koji ga interesuje.

Kako uz tako moćnu konkurenciju u tom digitalnom svetu, plasirati promotivni materijal tako da bude primećen i ostvari željeni efekat na posetioce. Treba razumeti da ne postoji univerzalan recept za kreiranje savršene, atraktivne promocije, može se samo ukazati na određene aspekte uobičajenih moždanih reakcija na advertajzing, kao i neke tehničke mogućnosti za dizajniranje potencijalno kvalitetnih promotivnih sadržaja. 


\section{PROMOCIJA I PAŽNJA}

Destinacija može biti predstavljena serijom izuzetno kvalitetnih $i$ atraktivnih fotografija, ali biće to samo serija slika u masi bezbrojnih sličnih prikaza. Smatra se da čovek informacije iz okruženja najviše prikuplja čulom vida, odnosno: "oko 90\% svih oseta koje imamo čine vidni oseti" (Rot, 1987: 72). Sledeći tu logiku, marketari se uglavnom baziraju na vizuelnim propagandnim porukama. Martin Lindstrom je više nego u pravu kada konstatuje: “Danas naše čulo vida trpi veću stimulaciju nego ikad, a studije pokazuju da što je ta stimulacija veća, to je zapravo teže privući našu pažnju“ (Lindstrom, 2010: 177).

Kako to ljudski mozak reaguje kao urođeni Adblocker? Kada korteks primi neku vrstu informacije koju smatra prioritetnom, šalje povratni signal delu poznatom kao talamički retikularni nukleus - TRN. To je tanak sloj neurona između talamusa i korteksa koji može funkcionisati kao pristupna vrata. TRN koristi neurotransmiter GABA za regulisanje talamokortikalne komunikacije i inhibiranje prenosa drugih manje zanimljivih signala iz talamusa $u$ korteks. $U$ saradnji $s$ asocijativnim korteksom (preko talamokortikalno-talamičke petlje), talamus može obaviti modulaciju primljene informacije povećanjem esencijalnih signala. Stoga treba imati na umu da se mogu zapamtiti samo sadržaji koji su predmet pažnje. Sadržaj koji je odbačen filtracijskim procesom, za svesnu komponentu mozga zapravo nije se dogodio. Ova selektivna obrada bihevioralno relevantnih senzornih inputa i potiskivanje nebitnih sadržaja, jedna je od osnovnih kognitivnih funkcija, što posebno treba imatu na umu tokom kreiranja promotivnih sadržaja.

Neurofiziološka skeniranja mozga otkrivaju da vizuelne prezentacije, na primer logo firme u kombinaciji sa audio podražajem ili odgovarajućim mirisom potpuno angažuju čula, osećaj je prijatniji i takve kombinovane reklame se pamte! Ova kombinacija se zove čulni brending - Sensory Branding. U svojoj knjizi Čulni marketing (Sensory Marketing), autori Hulten i saradnici ističu ulogu i značaj pet ljudskih čula koja su od presudnog značaja u građenju individualnog iskustva u kupovini i potrošačkom procesu uopšte (Hulten, Broweus \& Van Dijk, 2009: 1). Hulten senzorni brending definiše kao tip marketinga koji afektuje na sva čula kreirajući tako emocionalne asocijacije kod potrošača, odnosno kaže da su to martketing tehnike koje imaju za cilj da zavedu potrošača upotrebom njegovih čula, i tako povećaju uticaj na njegova osećanja i ponašanje (Hulten, 2011: 256273).

Proces snažnog delovanja mirisa na mozak u neurofiziološkom smislu objašnjiv je na sledeći način: svi senzorni putevi, transdukcioni putevi čulnih informacija, vode do određenih centara u kori velikog mozga, ali preko talamusa (kortikalno-talamička-kortikalna petlja). Kroz saradnju korteksa i talamusa neke 
senzorne informacije mogu biti pojačane, dok sadržaji koji nisu u fokusu pažnje bivaju oslabljeni ili čak potisnuti u potpunosti. Jedan deo mirisnih nervnih vodova konektovan je direktno za korteks, zaobilazeći talamus tako zaobilazi mogućnost moždane filtracije, izvan kontrole je, i to je razlog da se miris, bio prijatan ili jako loš, jednostavno ne može ignorisati (Tanasić, 2019: 11-14).

Kompanija ATC, koristeći Hipersonic Sound Sistem, uz saglasnost FDA, US Food and Drug Administration - Uprava za kontrolu hrane i lekova, razvila je uređaj koji može da se montira na ulične automate, spoljašne displeje, reklamne panoe, itd. Zvuk se direktno projektuje na tačno određen prostor, tako da kada neko uđe u zahvat projektovane zone, može čuti zvuk, poruku ili reklamu, nečujnu za sve ostale oko njega (Gray, 2005: 6). U kombinaciji sa video materijalom, mirisima, specijalno emitovanim audio sadržajima, uređaj može prirediti izvanrednu multisenzornu promotivnu atrakciju koja će se trajno memorisati.

\subsection{Virtuelna stvarnost (Virtual Reality - VR)}

Virtuelna stvarnost je tehnologija kojom se kreira digitalni novi svet, i on može biti realan, delimično realan ili potpuno fiktivan, (posebno u video igricama), kroz koji se korisnik kreće. To je trodimenzionalno kompjuterski generisano okruženje koje korisniku pruža osećaj realnog okruženja, daje mu mogućnost da manipuliše određenim objektima, kao i da izvodi raznovrsne aktivnosti. Ovi veštački prizori se emituju 2D tehnologijom, razdvajaju se levi i desni kanal, tek upotrebom specijalnih naočara (vizira ili kaciga), u mozgu korisnika se spajaju, tako se dobija efekat treće dimenzije, odnosno dubine - generiše se 3D doživljaj. Postoje razni sistemi virtuelne realnosti ali svi oni imaju zajedničku osobinu a to je sposobnost kreiranja trodimenzionalnog doživljaja. Kroz uređaje za kreiranje virtuelne stvarnosti omogućeno je korisniku da iskusi širok dijapazon avantura, od virtuelnog gostovanja na koncertu klasične muzike ili neke svetske rok atrakcije, do krstarenja međuzvezdanim prostorima udaljenih galaksija.

Virtuelno okruženje treba da omogući adekvatan odgovor u realnom vremenu, dok korisnik istražuje novi prostor u koji je virtuelnom tehnologijom transportovan. Starijim modelima, nedovoljno usavršenim, dešavalo se da dolazi do odlaganja, kašnjenja reakcija virtuelno kreiranog okruženja. Tako nastao problem izaziva reakciju korisnika koji postaje svestan manjkavosti veštački kreiranog prostora, što narušava kvalitet doživljenog. Samo savršeni sistemi, koji omogućavaju potpuno slobodnu, nesputanu interakciju korisnika i uređaja u realnom vremenu, rezultiraju fantastičnim, nezaboravnim iskustvima. Kvalitetno 
dizajniran virtuelni softver u stanju je da sinhronizuje pokrete glave i očiju korisnika sa adekvatnim odgovorom sistema, što rezultira promenom percepcije, odnosno osigurava doživljaj virtuelnog sistema kao realnog i korisniku prijatnog.

Istina da je virtuelna realnost svoju prvobitnu primenu imala $u$ industriji zabave, aplicirana kroz izuzetno atraktivne video igrice, danas se primenjuje $u$ različitim oblastima:

- Medicina;

- Sport;

- Umetnost;

- Arhitektura;

- Vojne obuke;

- Zabava;

- Turizam.

Virtuelna stvarnost je kreiranje digitalnog okruženja sposobnog da korisnika prenese u drugi svet, $i$ to tako realno kao da je zaista prisutan tamo. Primenom savremene tehnologije i složenih softvera, dodavanjem digitalnog sveta, dizajniraju se okruženja tako verna da korisnik ima percepciju, da na primer, zaista sedi u komandnom modulu međugalaktičkog šatla. Realno se očekuje u budućnosti raznovrsna primena ove tehnologije, posebno u oblasti komunikacija ali $\mathrm{i}$ edukacije i treninga u mnogim oblastima.

Pretpostavka je da će atak na veći broj čula potrošača tokom promocije, adekvatno povećati snagu poruke, njen uticaj i emocionalnu povezanost sa promovisanim. Danas marketari imaju na raspolaganju tehnike i alate za primenu i izazivanje raznovrsnih senzacija. Primenom nove tehnologije moguće je prirediti izuzetna čulna iskustva potrošačima, takva da imaju utisak naučno-fantastičnog putovanja.

Novi Teleporter uređaj 4D tehnologije koji upotrebljavaju hoteli lanca Marriott dizajniran je da korisnicima pruži nezaboravno putovanje. Uz pomoć Oculus Rift tehnologije gostima hotela je omogućeno da virtuelno posete destinacije na Havajima, uz osećaj da su fizički teleportovani na prelepe plaže. Korisnik teleportera može da oseti atmosferu okruženja, uz ugrađene grejače na specijalno dizajniranim naočarima doživljava simulaciju toplote sunca na licu, dok istovremeno fine vodene prskalice raspršuju kapljice vode po koži, simulirajući vožnju brzim gliserom (Blackwood, 2014). Uz ovakvu virtuelnu vožnju, adekvatan miris bi upotpunio interaktivni multisenzorni sadržaj koji će sigurno biti u fokusu pažnje, podići nivo adrenalina, i takvo doživljeno iskustvo ostaje trajno memorisano. 


\subsection{Proširena stvarnost (Augmented Reality - AR)}

Augmentovana stvarnost, (Augmented reality - proširena stvarnost), predstavlja jedan od najvećih razvojnih tehnološkoh trendova današnjice. Procenjuje se intezivno širenje ove tehnologije razvojem pametnih telefona (AR Ready Smarphones) i ostalih komunikacionih uređaja prilagođenih tehnologiji proširene stvarnosti. Kombinovanjem digitalnih tehnologija i čulnih utisaka koje proizvode na korisnika, moguće je kreirati virtuelnu stvarnost (Virtual Reality - VR), kao i augmentovanu stvarnost (Augmented Reality - AR). Obe tehnologije su varijacije Virtual Enviroments - VE, i proizvodeći specifične utiske modeluju način viđenja i doživljaj okolnog sveta, odnosno može se reći da tako povezuju digitalni i fizikalni, objektivni svet. Osnovna osobina koja diferencira tako kreirane digitalizovane svetove jeste što virtuelna realnost dizajnira potpuno novo okruženje kroz koje se korisnik kreće, nasuprot augmentovanoj realnosti koja u realno okruženje ubacuje digitalizovane objekte.

Za razliku od virtuelne realnosti koja koristi sintetičko okruženje, augmentovana realnost (proširena stvarnost), korisniku prikazuje realno okruženje u koje implementira virtuelne, odnosno digitalne objekte. Proširena stvarnost predstavlja interaktivno iskustvo, poboljšan varijetet stvarnog fizičkog okruženja, čiji se elementi nadopunjuju kompjuterski generisanim objektima, ponekad i preko nekoliko senzornih modaliteta (vizuelni, audio, somatosenzorni).

Ronald Azuma je još 1997. godine definisao augmentovanu realnost kao tehniku koja ne zamenjuje stvarnost u potpunosti, već je dopunjuje, proširuje realno iskustvo uz pomoć virtuelnih informacija i objekata koji korisnicima omogućavaju da bolje vide svet oko sebe i pojačaju sopstvene individualne doživljaje (Azuma, 1997: 356).

Augmentovana realnost se ostvaruje kombinovanjem stvarnih i digitalnih objekata iz okruženja, interakcijom u realnom vremenu a sve to kroz 3D generisan prikaz. Digitalizovan sadržaj projektovan u realni, fizikalni svet, daje utisak korisniku integrisanog, jedinstvenog prostora, iskustvo koje izjednačava doživljaj digitalnog sa realnim okruženjem. Softver augmentovane realnosti omogućava jednostavnu integraciju digitalnog i realnog sveta. Dovoljno je kamerom mobilnog uređaja snimiti neki objekat ili prostor i preklapanjem ovih svetova kombinovati po želji digitalno i realno.

Jedna od prvih kompanija koja aplicira augmentovanu stvarnost bila je lkea. Koristili su kamere za snimanje svojih proizvoda na sajmu nameštaja, i primenom posebnog softvera, posetioci su mogli da preko snimaka svog enterijera, virtuelno ubacuju komade nameštaja iz Ikeinog proizvodnog programa. Kasnije se sistem unapređuje, korisnici bi na ulazu u Ikein prodajni prostor, u svoje mobilne uređaje 
instalirali program za primenu softvera augmentovane realnosti. Na taj način omogućeno je da svojim mobilnim telefonom snime na primer, trosed i da ga zatim digitalno kombinuju, implementiraju na snimak svoje dnevne sobe. Korisnik može da menja položaj odabranog komada nameštaja, da menja boju materijala kojim je trosed presvučen, pa čak da mere prilagodi svojim željama i potrebama, čime ostvaruje punu interakciju digitalnog objekta i realnog okruženja.

Kombinovanje računarski generisanih objekata i stvarnog okruženja ubrzo primenjuje $B M W$ na sajmovima automobila i u svojim prodajnim objektima. Posetioci mogu da instaliraju softver za primenu augmentovane stvarnosti i zatim kreiraju unutrašnjost automobila ili boju karoserije. Potencijalni kupci mogu da menjaju opremu, boju presvlaka, sedišta, uopšte da kreiraju unikatni model po svom nahođenju i naravno količini novca koji su spremni da odvoje za ispunjenje svojih želja.

Tehniku augmentovane stvarnosti uveliko primenjuju aerodromi širom sveta. Putnicima su na raspolaganju kombinovane informacije koje znatno olakšavaju pronalazak mesta za ukrcavanje u vazduhoplov, nalaženje prtljaga, mesta za susret sa nepoznatim poslovnim partnerom (miting point), pronalaskom bifea, ili najbližeg restorana i slično.

Posebno interesantna tehnologija u promociji turističkih destinacija može biti upotreba dronova. Male gotovo nečujne leteće mašine, opremljene kamerama mogu destinaciju sagledati iz neobičnog ugla, i obezbediti fantastične snimke iz ptičije perspektive. Zamak, crkva i uopšte visoke građevine, prezentuju se na nov, neviđen način. Klasično snimanje može biti upotpunjeno i infracrvenim ili laserskim skeniranjem, što dodatno proširuje mogućnost prikaza objekata. Kompjuterskom obradom laserskog skeniranja, trodimenzonalno se modeluje snimljeni objekat, što svakako povećava atraktivnost promotivnog materijala.

Sadašnje aplikacije proširene stvarnosti uključuju vizuelizaciju različitih proizvoda, virtuelna testiranja, (probne vožnje, automobila, skutera itd), trenažu pilota civilne i vojne avijacije, radarskih operatera na aerodromima i mnoge druge obuke. Opravdano je očekivati da će ova napredna tehnologija biti usavršavana i da će se znatno proširiti broj oblasti u kojima se može uspešno primeniti.

\section{ZAKLJUČAK}

S obzirom na to da mozak nema dovoljno kapaciteta da obradi sve senzorne informacije koje neprestano pristižu, određene grupacije ćelija u prefrontalnom korteksu specijalizovale su sposobnost da potiskuju informacije manjeg značaja, 
odnosno inpute za koje u datom trenutku ne postoji interesovanje. Ova pojava se naziva moždana filtracija (Brain filtering) i omogućava fokusiranje na signale od interesa, potiskujući sve ostale. Cilj marketing komuniciranja je da ubedi potrošače da kupuju turističke proizvode, pa čak da kreira nove navike i potrebe potencijalnih turista. Tako i svakodnevna komunikacija, prenošenje poruka, ideja, informacija suočava se sa problemom pažnje recepienta, zapravo koliko je fokusiran, ili želi da bude fokusiran na sadržaj kojem je izložen. Ova saznanja mogu biti od koristi, odnosno imati praktičnu primenu u kreiranju promotivnih poruka, uočavanju i otklanjanju potencijalnih problema koji mogu nastati kao posledica selektivne obrade senzornih signala.

Proširena stvarnost predstavlja interaktivno iskustvo, poboljšan varijetet stvarnog fizičkog okruženja, čiji se elementi nadopunjuju kompjuterski generisanim objektima. Kombinovanje računarski apliciranih objekata i stvarnog okruženja, omogućava unikatne kreacije, prilagođene individualnim potrebama i ukusu potrošača. Osnovna osobina koja diferencira tako kreirane digitalizovane svetove je u tome što virtuelna realnost dizajnira potpuno novo okruženje kroz koje se korisnik kreće, nasuprot augmentovanoj realnosti koja u realno okruženje ubacuje digitalizovane objekte.

Digitalni marketinški kanali u funkciji su da vrednost turističkog proizvoda, odnosno turističke destinacije prenesu na krajnjeg potrošača. Digitalni marketing obuhvata brojne alate i mogućnosti, tako da uz nisku cenu promovisanja i mogućnosti da istovremeno dopre do velikog broja potencijalnih potrošača, predstavlja izuzetno efikasan model savremenog poslovanja turističke kompanije.

\section{LITERATURA}

1. Blackwood, J. (2014). Marriott Hotels, Get Teleported Event Utilizes Oculus Rift Technology Available at: https://mytechdecisions.com/mobility/marriott-hotels-getteleported-event-utilizes-oculus-rift-technology/ (10.07.2020)

2. Copeland B. J. (2005). Colossus: The Secrets of Bletchley Park's Codebreaking Computers, Oxford: Oxford University Press, p.75

3. Gray T. (2005). The use of Sound for Control, Healing and Emprowement, Mills College, USA

4. Hood M. J. (2005). Selling the dream: Why Advertising is Good Business, Westport, Praeger Publishers 
5. Hulten B. (2011). Sensory marketing: the multy-sensory brand-expirience concept, European Business Review, Vol. 23, Issue 3, 256-273

6. Hulten B., Broweus N. \& Van D. M. (2009), Sensory Marketing, New York, Palgrave MacMillan

7. Internet Usage Statistic, (2020), World Internet Users and 2020 Population Stats Available at: https://www.internetworldstats.com/stats.htm

8. Lindstrom M. (2010). Kupologija - istine i laži o tome zašto kupujemo, Beograd: Laguna

9. Rot N. (1987). Opšta psihologija, Beograd: Zavod za udžbenike i nastavna sredstva

10. Scott W. D. (1904). The Psychology of Advertising, Atlantic Monthly, 93, January, 1904

11. Statista. (2020). Forecast number of mobile devices worldwide from 2019 to 2023 Available at: https://www.statista.com/statistics/245501/multiple-mobile-deviceownership-worldwide/

12. Tanasić R. B. (2019). Moždana filtracija u komunikaciji, V konferencija BLC - Mediji i ekonomija, Banja Luka College 2019, Vol. 2(2), str. 11-14

Рад је примљен: 20. август 2020. Прихваћен за објављивање: 30. август 2020.

Received: August 20, 2020.

Accepted: August 30, 2020. 